\title{
Abscess removal in a desert horned viper (Cerastes cerastes)
}

\section{Puveanthan Nagappan Govendan ${ }^{1, *}$, Michael Nadhor Nainggolan ${ }^{2}$, Erika $^{3}$, Slamet Raharjo ${ }^{4}$}

\author{
${ }^{1}$ Faculty of Veterinary Medicine, Gadjah Mada University, Yogyakarta, Indonesia \\ ${ }^{2}$ Sunset Vet Bali, Bali, Indonesia \\ ${ }^{3}$ Faculty of Veterinary Medicine, Udayana University, Bali, Indonesia \\ ${ }^{4}$ Department of Internal Medicine, Faculty of Veterinary Medicine, Gadjah Mada University, Yogyakarta, Indonesia
}

\begin{abstract}
Venomous snakes are widely kept in captive as collections by private reptile keepers. A 7 years old male desert horned viper (Cerastes cerastes) was presented with a lump on the caudal part of the body. Proper physical restraining method using snake hook and transparent tubes was performed for clinical examination and radiography. Two radiography views revealed radiopaque in both lateral and dorsal recumbence. Differential diagnosis was tumor growth and abscess. Surgical intervention was indicated and performed with the viper induced with injectable anesthesia and maintained with gas anesthesia. Surgical correction with manually removing the abscess was performed. The NSAID, broad spectrum antibiotic, topical antibiotic and fluid therapy were performed post-surgery. Six weeks post-surgery the suture material was removed and wound was dry and healed well.
\end{abstract}

\section{Keywords:}

abscess removal, Cerastes cerastes, radiography, surgery

\section{INTRODUCTION}

Captive venomous snakes are usually found in zoos, research collections and the private reptile collections (Lock 2008; Wilkinson 2014). The desert horned viper (Cerastes cerastes) is a venomous viper from the desert of North Africa (Grano 2016). Non-native species venomous snakes could be really dangerous for veterinarians and keepers due to the absence of antivenin for the venom. Most reptile owners should be aware that very few veterinarians would accept venomous reptiles, being a non-native would mean more dangerous. This paper discusses how to treat abscesses in desert horn venomous snakes that have never been reported in Indonesia.

\section{- CASE}

Anamnesis and signalement: A 7 year old captive raised Cerastes cerastes (C. cerastes) was presented with a lump on the caudal part of the body. The particular snake was not brought into any veterinary clinics because the owner was unaware of veterinarians who do treat venomous reptiles. There were no complains of anorexic or behavioral changes were noticed. The particular specimen also had been defecating normally and urates were produced with no abnormality. That gave an idea that the cloaca is not affected clinically. Rodent-bite could have led to this infection with history that the snake was always offered live prey. Live prey feeding is still very common practice among private reptile keepers in Indonesia.
Clinical examination: Snake hook and a proper size transparent snake restrain tube was used to manually restrain the C. cerastes. The snake was first lifted out of the tube using a snake hook by gently inserting the hook under the anterior part of the snake's body (Fig. 1A). The snake was then manually guided into the cylindrical transparent restrain tube. When one third part of the snake's body was entering into the tube, the snake and the tube then grasped for manual hand fixation. It is important to estimate the proper size for tubing for safe restraint and to make sure the snake cannot turn around inside the tube (Lock 2008; Wilkinson 2014).

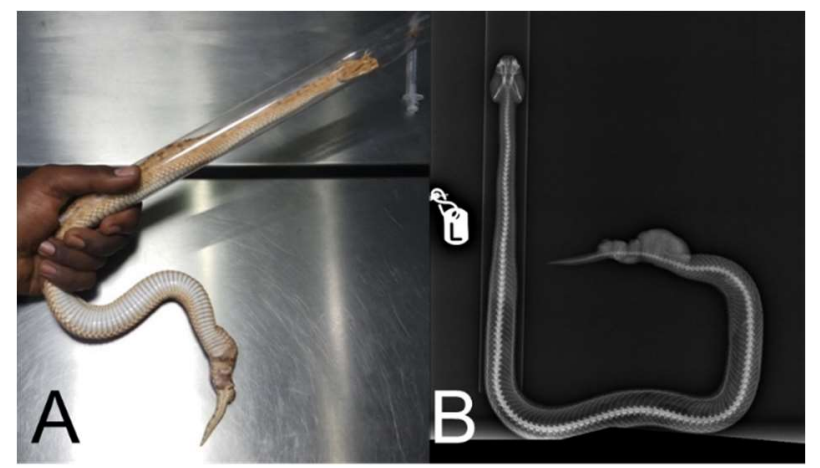

Figure 1 The Cerastes cerastes placed into a transparent tube for closer physical inspection and treatment (A) and dorso-ventral radio image view of the C. cerastes (B).

Radiography: The mass was inspected at the caudal part of the body (dorsal and lateral to the cloaca and the base of the

Received: 30-04-2020 | Revised: 28-05-2020 | Accepted: 10-06-2020

(C) 2020 CC-BY-SA. This is an Open Access article that is distributed under the terms of Creative Commons Attribution ShareAlike 4.0 International License (https://creativecommons.org/licenses/by-sa/4.0/). 
tail. Palpation of the mass was solid. Snake was brought for radiography while being in the restrain tube (Fig. 1B). Radiography was performed lateral and dorsal recumbence. Radiographs showed radiopaque imaging on both views.

Differential diagnosis: Tumor growth and abscess.

Diagnose: Based from the anamneses, clinical symptoms and radiography, the lump on the caudal body part of $C$. cerastes was diagnosed with abscess. Subcutaneous abscess is common in captive reptiles (Divers 1999; Di-Girolamo \& Mans 2016).

Prognosis: The prognosis of this case was good to guarded (fausta to dubius). Abscesses treatment with only antibiotics often does not give maximal results in reptiles (Mader 2006). When the abscess is removed completely, prognosis is good (Hoppmann \& Barron 2007). Debridement of skins and around the flesh was done to facilitate the regeneration of the epithelium (Mitchell \& Diaz-Figueroa 2004).

\section{口 TREATMENT}

Anesthesia: One third of the snake body was fixated into the snake-tube. Induction anesthesia of Zoletil $50 \AA$ (tiletamine $\mathrm{HCl}$ - zolazepam $125 \mathrm{mg} / \mathrm{ml}$ ) with a dose of $7 \mathrm{mg} / \mathrm{kg} \mathrm{BW}$ was given intramuscular at the cranial one third part of the body. The snake was then directly given Isoflurane at $2 \%$ and oxygen $0.4 \%$. After 4 minutes, isoflurane was reduced at 1 $\%$. An intravenous cannulation just with the hub and catheter with removed needle and the flashback chamber was used as an endotracheal tube. Restrain tube was then removed and the $C$. cerastes was manually restrained and the catheter was placed into the epiglottis. A 2.0 endotracheal tube was then placed on the edge of the catheter's hub. Isoflurane was then adjusted at $1 \%$.

Surgery: Area of the growth site was disinfected with alcohol $70 \%$. Draping was placed on the growth site. Scalpel and scissors was used to open the growth site. Fibrous capsuled abscess was then removed manually one by one with a non-toothed forceps. Best results often with complete removal of the abscesses and the surrounding fibrous capsules (Mader 2006). The cloaca was noticed free of infection after removal of the all the purulent. Surgical site was then flushed with sodium chloride $0.9 \%$ solution and topical antibiotic Bio-placenton ${ }^{\circledR}$ contains combination of neomycin sulfate $0.5 \%$ and bovine placenta extract $10 \%$ was applied at the surgical site. Excessive skin of the snake was removed but consideration of skin tension was taken under consideration for integument recovery. Skin was stitched with absorbable suture material with interrupted lambert suture method.

Post-surgery treatment: Topical antibiotic of Bioplacenton ${ }^{\circledR}$ was then again applied superficially. Bioplacenton $\AA$ contains bovine placenta extract and neomycin sulphate which promotes sufficient wound healing. Parenteral antibiotic of Enrofloxacin was administered at a dose of 10 $\mathrm{mg} / \mathrm{kg} \mathrm{BW}$. Enrofloxacin is one of the most common antibiotics used in reptiles with dermatological lesion (White et al. 2010). Meloxicam was administered at a dose of 0.2 $\mathrm{mg} / \mathrm{kg} \mathrm{BW}$. Fluids of RL and $\mathrm{NaCl}(1: 1)$ were administered $\mathrm{SC}$ with a dose of $20 \mathrm{ml} / \mathrm{kg} \mathrm{BW}$. Post-surgery treatments consist of antibiotic, NSAID and fluids were continued. Enrofloxacin $(2.5 \%)$ at $10 \mathrm{mg} / \mathrm{kg} \mathrm{BW}$ was administered IM daily for 10 days. Meloxicam $(0.1 \mathrm{mg} / \mathrm{ml})$ was administered every 48 hours for 3 times. Fluid therapy consists of $\mathrm{NaCl}$ $0.9 \%$ at a dose of $20 \mathrm{ml} / \mathrm{kg}$ SC for 6 days.

Wound healing: Six weeks post-surgery the suture material was removed, the wound was dry and healed well.

\section{- CONCLUSION}

Surgical correction with manually removing the abscess of subcutaneous infection was the only method for treatment on a Cerastes cerastes. Post-surgery antibiotic, anti-inflammatory drugs, pain management and fluids were administered for wound healing process.

\section{- AUTHOR INFORMATION}

Corresponding Author

*PNG: puvean89@gmail.com

Faculty of Veterinary Medicine, Gadjah Mada University, Yogyakarta, Indonesia

\section{- ACKNOWLEDGMENT}

Thank you to Sunset Vet Bali for sponsoring us on this case. We would also like to thank Professor Zdenek Knotek, Dr. Matteo Oliveri, Dr Eva Cermakova who gave us great inputs working on this case.

\section{REFERENCES}

Divers SJ. 1999. Clinical evaluation of reptiles. Veterinary Clinics of North America Exotic Animal Practice. 2(2):291-331.

Di-Girolamo N, Mans C. 2016. Reptile soft tissue surgery. Veterinary Clinics of North America Exotic Animal Practise. 19(1):97-131.

Grano M. 2016. Cerastes cerastes. Biodiversity Journal. 7(3):295-386.

Hoppmann E, Barron HW. 2007. Dermatology in reptiles. Journal of Exotic Pet Medicine. 16(4):201-224.

Lock B. 2008. Venomous snake restraint and handling. Journal of Exotic Pet Medicine. 17(4):273-284.

Mader DR. 2006. Reptile Medicine and Surgery, 2nd ed. WB Saunders, Elsevier.

Mitchell MA, Diaz-Figueroa O. 2004. Wound management in reptiles. The veterinary clinics of North America. Exotic animal practice. 7(1):123-140.

White SD, Bourdeau P, Bruet V, Kass PH, Tell L, Hawkins MG. 2010. Reptiles with dermatological lesions: a retrospective study of 301 cases at two university teaching hospitals (1992-2008). Veterinary Dermatology. 22(2):150-161.

Wilkinson SL. 2014. Guide to venomous reptiles in veterinary practice. Journal of Exotic Pet Medicine. 23(4):337-346. 